January 2008

\title{
Causes, magnitude and management of burns in under-fives in district hospitals in Dar es Salaam, Tanzania.
}

M. Justin-Temu

Muhimbili University of Health and Allied Sciences, Tanzania

G. Rimoy

Muhimbili University of Health and Allied Sciences, Tanzania

Zul Premji

Aga Khan University, zul.premji@aku.edu

G. Matemu

Muhimbili University of Health and Allied Sciences, Tanzania

Follow this and additional works at: http://ecommons.aku.edu/eastafrica_fhs_mc_pathol

Part of the Pathology Commons

\section{Recommended Citation}

Justin-Temu, M., Rimoy, G., Premji, Z., Matemu, G. (2008). Causes, magnitude and management of burns in under-fives in district hospitals in Dar es Salaam, Tanzania.. East African journal of public health, 5(1), 38-42.

Available at: http://ecommons.aku.edu/eastafrica_fhs_mc_pathol/67 


\title{
CAUSES, MAGNITUDE AND MANAGEMENT OF BURNS IN UNDER-FIVES IN DISTRICT HOSPITALS IN DAR ES SALAAM, TANZANIA.
}

\author{
M. Justin-Temu ${ }^{1}$, G. Rimoy², Z. Premji ${ }^{3}$, G. Matemu ${ }^{1}$
}

\begin{abstract}
Objectives: To determine the causes, magnitude and management of burns in children under five years of age who were admitted in the district hospitals of Dar es Salaam City, Tanzania.

Methods: In this study, a total of 204 under fives were enrolled. Questionnaires were used to elicit if the parent/caretaker had the knowledge of the cause of the burns, what was done immediately after burn injury, first aid given immediately after burn, source of the knowledge of first aid and when the child was taken to the hospital. Also the questionnaire was cited with data on the management of burns in the hospitals through observation and checking the treatment files.

Results: Forty nine percent were males while 50.5\% were females. Most of the children (54.9\%) were aged between 1-2 years. 78.4 $\%$ had scalds while $21.6 \%$ had flame burns. No children were found to have burns caused by chemicals or electricity. Most of the burns $(97.5 \%)$ occurred accidentally, although some (2.5\%) were intentional. $68.6 \%$ of these burn injuries occurred in the kitchen. Immediately after burn $87.3 \%$ of the children had first aid applied on their wounds while $12.7 \%$ didn't apply anything. Of the agents used, honey was the most used $(32.8 \%)$ followed by cold water $(16.7 \%)$. The source of knowledge on these agents was from relatives and friends $(72.5 \%)$, schools $(7 \%)$, media $(6 \%)$ and medical personnel $(14 \%)$. The study further revealed that analgesics, intravenous fluids, antiseptics and antibiotics were the drugs used for treatment of burns in the hospital and that there was no specialized unit for burns in the hospitals.

Conclusions: Causes of childhood burns are largely preventable requiring active social/medical education and public enlighten campaigns on the various methods of prevention. The government to see to it that hospitals have specialized units for managing burn cases and also the socio-economic status of its people be improved.
\end{abstract}

Key word: Burns, Under-fives, Cause, Management

\section{Introduction}

Burn is a tissue damage caused by such agents as heat; electricity, sunlight or nuclear radiation. Burn injury affects all human kind and especially children under five years of age (1). It is among the most serious injuries man can come across with and remains a major health problem in the world. Most burns occur at homes; causes being due to scald i.e. hot fluids, and flame as indicated in studies conducted in Dar es Salaam and elsewhere $(1,2)$. In the United States more than 1.25 million people sustain burns every year (2).

In adults the most common thermal burns are those due to flame (40-45\%) while in children thermal scalding i.e. by hot fluids is the most common $(1,3)$. It was observed that burn injury was the leading cause of death from the non-transport injuries in Nairobi, Kenya (4).

Some of the factors that contribute to incidence of burn injury in the developing world include poor architectural design of the cooking places with open fires at floor levels and sometimes in the open place (5-6). While one study (7) reported that scalds were the leading causes of burn injury in children, other causes of burn included inflammable gas or vapour or the discharge of electricity and the chemical burns resulting from industrial accidents or assaults $(3,7-9)$.

A burn wound is classified as the first, second or third degree burn injury depending on the extent and depth of injury to the skin. First-degree burn involves only the top layer of the skin. The skin is hot red but no swelling or blistering. Second-degree burn involves the epidermis layer of the skin as well as the dermis.

Correspondence to: M. Justin-Temu, P. O. Box 65001, School of Pharmacy. E-mail: mtemu@muhas.ac.tz.

${ }^{1}$ Dept of Pharmaceutics, School of Pharmacy, MUHAS; ${ }^{2}$ Dept of Clinical Pharmacology, School of Medicine, MUHAS; ${ }^{3}$ Dept of Parasitology, MUHAS
The skin is light, red and blistery somewhat swollen moistly oozing, and the pain is severe. Third degree burn involves the full thickness of the skin where there is destruction of nerves and blood vessels. There is little pain at first, the burn area is yellow, cherry red and becomes dry and leathery.

In adults, the extent is determined by the Walluce's Rule of nine, which divides the body by surface area: Each upper limb $9 \%$, each lower limb $18 \%$, anterior and the posterior trunk each $18 \%$, head and neck $9 \%$ and perineum and genitalia $1 \%(6,10)$.

Honey has been used for a long time in the management of burn wounds (10). The Egyptians treated burns by mixture of gums, goat's hair and milk from a woman who had given birth to a son. Several local medications have been used in burn wound since the $20^{\text {th }}$ century. In 1925 Edward Clark Davison initiated the use of tannic acid spray, but in 1942 it was abandoned because of liver toxicity. Therefore the use of phenoleum gauze pressure dressing with electricity immobilisation was introduced, but it was abandoned because it didn't limit fluid loss. By $20^{\text {th }}$ century many dressing materials were introduced including the Mayer's historical use of silver nitrate soaks. Introduction of mefenide (sulfamylon) ushered in a new era of local antibacterial agent (10).

Current burn wound treatment ranges from debridement cleaning with normal saline and exposure treatment or simple dressing with a topical antimicrobial, use of artificial and other skin substitute and when necessary skin grafting. A dressing should be comfortable when applied or removed; a non-irritating and non-toxic should be applied to avoid infections.

Burn wound infection does occur necessitating the use of antibiotics despite application of the topical chemotherapy such as silver sulfadiazine, silver nitrate, providone iodine and chlorhexidine cream (11). Burn 
injury has a wide variation in terms of causes and there are many factors such as socio-economic, geographical etc affecting the causes/outcome and so there is a need to have a clear understanding of these factors. Therefore the aim of this study was to find out the causes, magnitude and management of burns in under-fives at home and in the three district hospitals in Dar es Salaam region.

\section{Subjects and Methods}

\section{Study area and population:}

The study design was a descriptive cross-sectional study. It was conducted between February and March 2004 in the paediatric wards in Amana, Mwananyamala and Temeke hospitals which are located in Ilala, Kinondoni, and Temeke municipalities in Dar es Salaam city respectively. In order to assess the causes and magnitude of burns, children less than five years of age with burn wounds that were admitted in the wards were eligible for the study. The parents/guardians/caretakers who participated in the interview were verbally informed about the study and were asked if they were willing to participate in the study. Everybody consented verbally to participate.

\section{Data collection and tools:}

Questionnaires were developed both in English and Kiswahili by the researcher. The Swahili version contained ten closed questions. The data were collected by the researcher through face-to-face interviews with the parents or caretaker of the children. A pilot study was done at Muhimbili National Hospital to pre-test the tool. The questionnaires elicited if the parents/caretakers had the knowledge by inquiring what aid was given to the child immediately after burn, where did they acquire the knowledge and if they have been educated on burns. Also the questionnaire was cited with data on the management of burns in the hospitals through observation and checking the treatment files.

\section{Sample size and sampling technique}

204 children were enrolled in the study, 180 children were with their parents while 24 were with guardians or other relatives. Convenience sampling was used.

\section{Data analysis}

The questionnaires were checked for completeness of the data filling at the end of each day and were then given serial numbers and coded before entering into the computer, and data were analysed using Epi-Info version 6.

\section{Ethical clearance.}

Ethical clearance was sought from relevant authorities from MUCHS: Permission was then asked from District Medical Officers and Medical Officers in charge of the respective hospitals. Verbal informed consent was obtained from the mothers or caretakers of the child in the studied facilities. The study was voluntary, and confidentiality was assured.

\section{Results}

During the period of February and March 2004, a total 204 children were hospitalised due to burn injury, 101 males and 103 females. 180 children were with their mothers while 24 were with a female guardian or relative. The study found out that the children were admitted for less than a week $(n=59)$, a week $(n=122)$ and more than a week $(n=23)$ after the burn injury. Fifty-five (54.9\%) percent of the children were between the ages of 1-2 years. The causes of burns were sought through the interview. Two main types of burn injury occurred; scald injuries from hot fluids or foods which were $78.4 \%$ while the remaining $21.6 \%$ were due to open flame from charcoal $(\mathrm{n}=13)$, lantern ("Kibatari") $(\mathrm{n}=11)$, candle $(\mathrm{n}=9)$ and kerosene stoves (8).

The relationship of causes of burn and the motive was explored. Of the total 204 burns, 97.5\% were accidental while $2.5 \%$ were established as intentional. The cause of burn injury was intentionally reported to be by parent, guardian or relative as a way of punishment, revenge or false beliefs. For the accidental one it was found that children were playing in the kitchen while their mothers, caretakers or relatives were cooking. The relationship between the causes and why the burn injury occurred are presented in Table 1. For the intentional burns (4 out 5) hot fluids or food were poured over the child.

Secondly the site where the burns occurred was established. In the majority the injury occurred in the kitchen, Figure 1. The Kitchen is the place where majority of cooking takes place and in which all hot fluids; food and open flame are mostly found. 68.6\% (140) children sustained burns in the kitchen. $21.6 \%$ (44) of the children were in the sitting room when the incident occurred while $9.8 \%(n=20)$ occurred in the bedroom an indication that some families have one single room used as bedroom, kitchen and living room.

Table 1: Relationship of causes and circumstances of accident

\begin{tabular}{lrcllr}
\hline Causes & \multicolumn{2}{l}{$\begin{array}{l}\text { Accidentally } \\
(\%)\end{array}$} & \multicolumn{2}{l}{$\begin{array}{l}\text { Intentionally } \\
(\%)\end{array}$} & Total (\%) \\
\hline Scalds & 156 & $(78.4)$ & 4 & $(80)$ & $160(78.4)$ \\
Flame & 43 & $(21.6)$ & 1 & $(20)$ & $44(21.6)$ \\
\hline Total & $\mathbf{1 9 9}$ & $(\mathbf{1 0 0 . 0})$ & $\mathbf{5}$ & $\mathbf{( 1 0 0 )}$ & $\mathbf{2 0 4}(\mathbf{1 0 0 . 0 )}$ \\
\hline
\end{tabular}




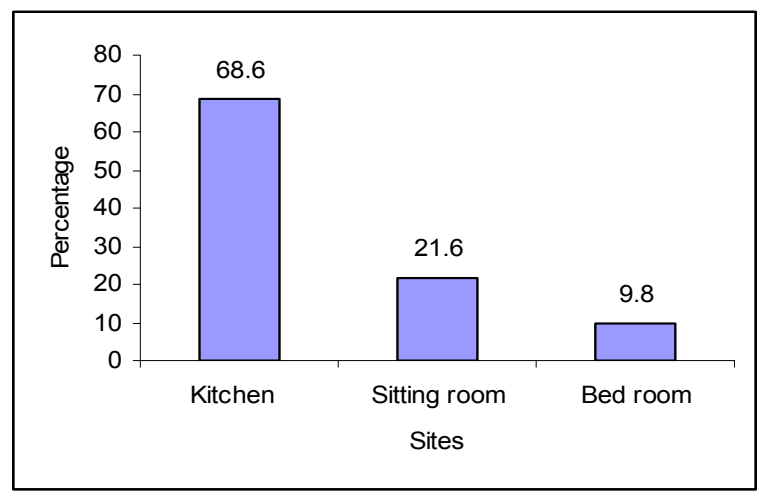

Figure 1. Distribution of place of accidents in the households.

With regards to what treatment was given as first aid immediately after the injury, majority of mothers/guardian mentioned many home remedies which were applied, some with deleterious effects of introducing infection, however majority applied time-tested honey. Table 2 shows the different home based remedies.

Various sources of knowledge on the first aid used were identified. Most of the Parents and Guardians got the knowledge from friends and relatives $(73 \%)$ as indicated in figure 2 .

Table 2: First aid given to the children immediately after burn.

\begin{tabular}{llc}
\hline First aid & $\begin{array}{l}\text { Frequency } \\
(\mathbf{n = 2 0 4 )}\end{array}$ & Percentage (\%) \\
\hline Honey & 67 & 32.8 \\
Cold water & 34 & 16.7 \\
Sugar & 20 & 9.8 \\
Raw eggs & 17 & 8.3 \\
Burn cream & 11 & 5.4 \\
Animal fur & 7 & 3.4 \\
Cooking oil & 7 & 3.4 \\
Vaseline & 6 & 2.9 \\
Animal dung & 3 & 1.5 \\
Charcoal & 3 & 1.4 \\
Mud & 2 & 1.0 \\
Kerosene & 1 & 0.5 \\
Nil & 26 & 12.7 \\
\hline Total & $\mathbf{2 0 4}$ & $\mathbf{1 0 0}$ \\
\hline
\end{tabular}

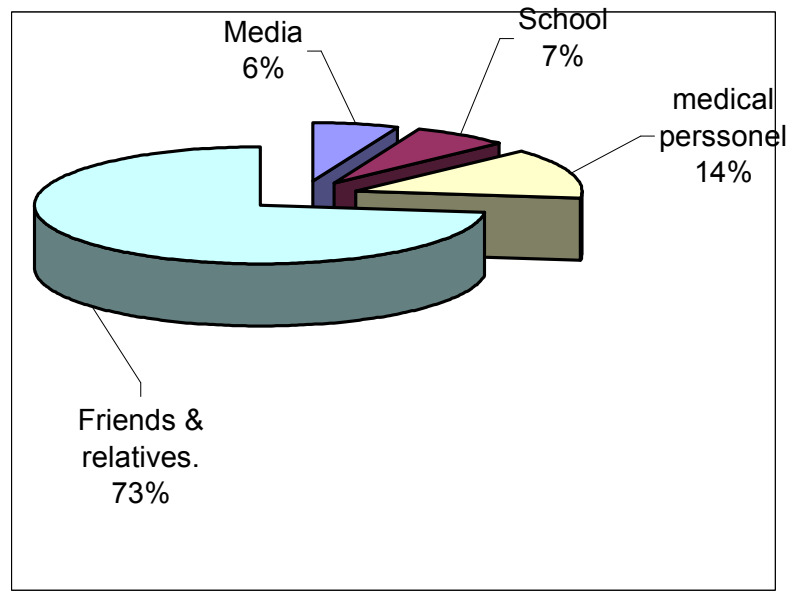

Figure 2. Sources of knowledge on the first aid used in burn.

Analgesics were given to the children in the hospitals as pain killers. The analgesics given were in the following order of magnitude: Paracetamol $60.3 \%$, Diclofenac $31.9 \%$, Pethidine $2.5 \%$ and Nimesulide 5.4\%. Also intravenous fluids were given to the children depending on degree of burn how much fluid was lost. Out of 204 children, 159 received intravenous fluids of which $80 \%$ were given Ringer Lactate while 20\% Dextrose/saline. Disinfectants and antiseptics were used for wound cleansing. Eusol was the most used agent (52\%) then dettol $(25.5 \%)$, and normal saline $(22.5 \%)$. After cleansing the wounds, they covered them using Povidone Iodine $41.2 \%$, Silverex cream $32.8 \%$, Sufratule $19.6 \%$ and Eusol $(6.4 \%)$.

Antibiotics also used in the management of burns where Gentamycin was the most used followed by Cloxacillin as single antibiotics, while Ceftriaxone and Cephalexin were the least used. Combination antibiotics were also used like gentamycin with cloxacillin (18\%) and gentamycin with ampiclox ${ }^{\circledR}$ (ampicillin with cloxacillin) (5\%). Figure 3 illustrates the antibiotics used in the management of burn injury. The magnitude of burn injury in each of the three hospitals was found by calculating the prevalence as follows: (Number of children admitted with burn in a given hospital x 100)/(Total number of children admitted in the ward)

It was found that the prevalence was 5.18\% (69/1331) for Amana hospital, 5. 42\% (64/1181) for Mwananyamala hospital and 4.31\% (71/1647) for Temeke hospital. 


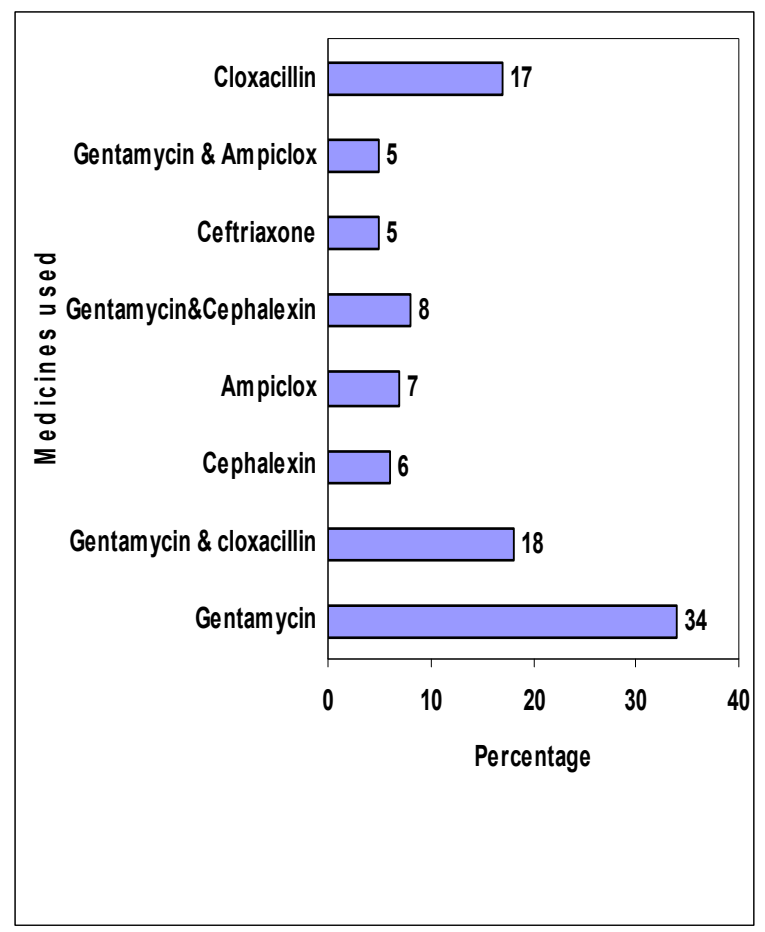

Figure 3. Antibiotics used in the treatment of burns

\section{Discussion}

The study showed that burn injury is a major problem for children of less than five years of age, with a prevalence of about 5\% for the children admitted in Amana, Mwananyamala, and Temeke hospitals, which are the three district hospitals in Dar es Salaam city.

The results showed equal sex distribution an indication that burns in children is not influenced by sex. It further showed that $55 \%$ of the children between $1-2$ years of age are very vulnerable to burns. These results are consistent with those found elsewhere $(1,7-8)$. These findings could be explained by the fact that this is the age children start walking without knowing what is harmful to them. Also cooking and feeding in the homes expose most of them because this group is either being carried by their mothers/caretakers while cooking or they are on the floor crawling or making a few steps while cooking processes are going on without any burn precautions. This puts them at risk of coming onto open fire, or hot fluids, objects or food. Thus inadequate parental/caretaker supervision in most circumstances where children are left unattended near fireplaces and hot fluids could explain the high incidence of burns in this group (1). Among the two etiologies of burn injuries found, scald was the most common cause of burn injuries which was similar to other studies $(1,7)$.

It was further found that most burns occurred accidentally $(97.5 \%)$ while $2.5 \%$ were intentional. Of those who got burnt intentionally, men caused four of them while a woman caused one. These intentional burns were associated with matrimonial conflicts or mischievous belief. In one case of belief, a woman believed that by burning the right leg of her youngest son she would succeed in her business.
Although most (68\%) of the burn injuries occurred in the kitchen it was interesting to find that the rest $(32 \%)$ occurred in the sitting room. This can be explained by the fact that some families seemed to be living in a single room where they do all activities including cooking, sleeping and recreation. Thus lack of enough space for children to play, during cooking and, storage of the hot fluids e.g. tea, porridge and water with uncovered containers in the single room results in burn injury of the children who can easily reach the hot stuff. Drinking hot beverages while holding or carrying infants, using table cloths or loose table mats that can be easily grabbed by the children can results in hot spills. These circumstances can explain why children aged less than 1 year are also involved in burn accidents. These accidents may be caused by placing flammable articles close to beds or at open spaces where children can easily reach them.

Furthermore, the study revealed that immediately after the burn injury several topical agents were applied as the first aid measures. Honey was the most applied agent $(32.8 \%)$ followed by cold water $(16.7 \%)$, while $12.7 \%$ didn't apply anything. Other agents like sugar, cooking oil, animal dung, animal fur, charcoal, mud, raw eggs, vaseline and kerosene were also applied. . The practice of applying topical agents on wounds immediately after burn as a first aid measure is a well-known practice through the ages (10). Honey has been used for wound treatment as long as 2000 years before bacteria were discovered to be the cause of infection. Recently honey has been reported to inhibit around 60 species of bacteria including aerobes and anaerobes, gram positive, gram negative and also antifungal action to Aspergillus spp and Penicillium spp (12). Its activity is based on its osmotic effect of its high sugar content and like other sugar syrups and sugar pastes has an osmolarity sufficient to inhibit microbial growth (13-15). Honey has also lymphocyte and phagocytic activity and to some extent activates the immune response to infection (16-17). Adverse reactions with honey are rare, and there was no adverse reaction noted other than a localized stinging sensation described by some patients which may be due to the acidity of honey as it has not been reported when the acidity is neutralized (18-20). Application of agents such as animal dung, mud etc may contaminate the wounds and lead to development of serious infections including tetanus and septic wounds thus prolonging the stay in hospital for treatment. Wound sepsis has been found as burn complications that could be due to first aid used by the mothers/caretakers $(1,19)$.

The source of knowledge on the first aid used was from relatives and friends $(72.5 \%)$, from school, $7.35 \%$, from the media, $5.9 \%$ and $14.2 \%$ from the medical personnel such as nurses, pharmaceutical workers and others. In all three-district hospitals, there were no specialized burn treatment facilities and all burn children were managed in the pediatric wards that also lack the special provision for nursing severe burns. Treatment of burns in the hospital showed that analgesics, intravenous fluids, antiseptics and antibiotics were the most used. Paracetamol was the commonest analgesics, $60.3 \%$, followed by diclofenac, $31.9 \%$, pethidine, $2.5 \%$ and nimesulide, $5.4 \%$. Two types of intravenous fluids were 
used i.e. Ringer Lactate, (79.9\%) and dextrose (20.1\%). The use of the intravenous fluids is important because when tissue is burned there is localized increased vascular permeability that allows ions and blood proteins to leak into the interstitial space. As well as initial loss of the blood plasma having proteins (especially albumin) moving out of the capillaries causing a decrease in intravascular oncotic pressure and therefore leads to tissue edema as more fluids enters the interstitial space along the osmotic gradient. Patients with severe and widespread burns can become profoundly hypotensive as a result of leakage of intravascular fluid.

Wound cleansing agents were used as follows: $52.8 \%$ eusol, 25.5\% dettol, and 22.5\% normal saline. Eusol is commonly used because is cheap and available compared to dettol. For covering the wounds povidone iodine was the most used agents $(41.2 \%)$ followed by silverex $\AA$ cream (32.8\%), sofratulle ${ }^{\circledR}(19.6 \%)$ and eusol (6.4\%).Although the preferred covering agent was silverex cream, it was not the most used because it is expensive and thus only few patients can afford to buy. The same applies to sofra-tulle. The antibiotics used included gentamycin (34\%) followed by cloxacillin $(17 \%)$ which were the most used as single antibiotics, while in combinations gentamycin with cloxacillin were most used $(18 \%)$ and gentamycin with cephalexin was the least.(5\%). Since a burn wound is likely to be infected with microorganisms such as Staphylococcus aureus, Proteus, Pseudomonas, E.coli, Enterobacter and Klebsiella the use of the combined antibiotics or the broad spectrum may help to eradicate these microorganisms.

The magnitude of the problem in each district hospital was found to be: $5.18 \%$ of burns occurred in Ilala District, $5.42 \%$ in Kinondoni, and $4.31 \%$ from Temeke. There was no significant difference in the three districts. Burn constitutes a major public health problem and needs to be prevented.

\section{Conclusion}

In conclusion, this study revealed that the children of under-five years of age who were more susceptible to burn injury were those aged between $1-2$ years where the most causative agent of these accidents was scald. Parents, guardians or the caretakers of children should be more careful in preventing their children from reaching the sources of burn. Health education should be given to the society regarding the first aid for burns and on fire-safety. The government to see to it that hospitals have specialized unit for managing burn cases and also the socio-economic status of its people be improved.

\section{References}

1. Mbaga FWM, Mwafongo VG. A Profile of Burn injury in Dar es Salaam, Tanzania. Tanzania Medical Journal 1998;3 (2): 8-12

2. Brigham PA, Mclonghlin E, Burn incidences and medical care in the United States, estimate trends and data sources. Journal of Burn care rehabilitation 1996; 17: (2) 95-107

3. Rossignol AM. Locke JA. Burke JF, Pediatric burn injuries in New England, USA Burns. 1990; 16(1):41-8.

4. Maniu E, Katsivo MN, Mwaura LW, and Amuyunzu M. Fatal Non-transpor Injuries in Nairobi Kenya, East African Medical Journal 1994; 71(6): 346-349.
5. Mabongunje OA, Khwaja MS, Lawrie JH. Childhood burns in Zaria, Nigeria Burns Including Thermal Injury 1987; 13(4): 298-304.

6. Demling RH. Burn injury. Acute care 1985; 11(3-4): 119-186

7. Kalayi GD. Burn Injuries in Zaria. A one-year prospective study. East Africa Medical Journal 1994;71(5): 317-321

8. Archbong AE, Antia UE, Udosen J. Childhood Burns in South Eastern Nigeria. East African Medical Journal 1997; 74(6): 382-384.

9. Judkins K; Burn resuscitation: What place albumin 2000; 6 1(2), 116-119

10. Artz CP. Historical aspects of burn management. Surgical Clinics of North America 1970; 50 (6); 1193-1200

11. Robotti EB. The treatment of burns: an historical perspective with emphasis on the hand. Hand clinics 1990; ;6(2):163-90

12. Molan PC. The antibacterial activity of honey. The anti bacterial activity of honey the nature of the antibacterial activity. Bee World.1992;73(1):5 28Bose B. Honey or sugar in treatment of infected wounds? Lancet 1982; 1 (8278): 7-11.

13. Green AE. Wound healing properties of honey. British .Journal of. Surgery 1988; 75 (12): 1278

14. Turner FJ. Hydrogen and other oxidants disinfectants $3^{\text {rd }}$ Edition. Philadelphia: Lea and Febiger; 1983

15. Abuharfeil N, Al-Oran $R$, Abo-Shehada $M$ R. The effect of bee honey on proliferate activity of human $B$ - and $T$ - Lymphocytes and activity of phagocytes. Food Agriculture Immunology 1999; 11: 169-177

16. Ahmed M, Shah M, Laby $S$. et al. Survey of surgical emergencies in a rura population in the Northern areas of Pakistan. Tropical. Medicine and Interna Health 1999; 4(12); 846-857

17. Tonks A, Coper RA, Price AJ. et. al. Stimulation of the-alpha release in monocytes by honey. Cytokine 2001; 14(4): 240-242

18. Kiistala R, Hannuksela M, Makinen-Kiljunen S, et.al. Honey allergy is rare in patients sensitive to pollens. Allergy 1995; 50(10) $844-847$

19. Betts JA, Molan PC. A pilot trial of honey as a wound dressing has shown the importance of the way honey is applied to wounds. In: Proceedings of the $11^{\text {th }}$ Conference of the European Wound Management Association in Dublin, Ireland 2001.

Received 2 July 2007; Revised 24 February 2008; Accepted 13 March 2008 